\title{
PROSEDUR PEMBERIAN KREDIT KEPEMILIKAN RUMAH (KPR) PADA PT. BANK TABUNGAN NEGARA CABANG LUBUK BUAYA PADANG
}

\author{
Firnando, Romi Susanto \\ Akademi Keuangan dan Perbankan \\ firnando291998@gmail.com
}

\begin{abstract}
This study to aims to determine what procedures must be fulfilled by prospective borrowers in applying for KPR credit at PT. Bank Tabungan Negara Lubuk Buaya Branch, Padang. This study uses a qualitative method which explains in description the procedures for proiding the procedures for providing KPR credit carried out by PT. Bank Tabungan Negara Lubuk Buaya Branch, Padang. Starting from the credit application procedure to the KPR credit monotoring process, is a stage of activity that involves several people in one or more departments to ensure harmony in the handling of a company's transactions.
\end{abstract}

Keywords : KPR credit procedure

\section{PENDAHULUAN}

Pertumbuhan dunia usaha serta bisnis saat ini sangat cepat, Pertumbuhan tersebut menghasilkan daya saing yang susah. Perbankan salah satu industri yang sangat cepat perkembanganya, baik dari sisi bisnis, pengelolaan dana warga ataupun pemberian kredit. Hal ini disebabkan adanya kebijakan pemerintah pada dunia perbankan. Oleh karna itu perbankan harus lebih kreatif agar bisa mewujudkan produk baru yang sesuai dengan kondisi pasar dan mencari sumber dana sebanyaknya. Dana dari warga merupakan jantung kehidupan perbankan, karna modal terbanyak merupakan dari warga, Dana dari warga yang terdapat dalam dunia perbankan menggapai $80 \%$ sampai $90 \%$, sebaliknya modal internal sekitar $10 \%$ sampai $20 \%$. Dana dari warga dalam bank berupa deposito, tabungan, giro serta dana pihak ketiga yang diterima oleh bank. dana yang dikumpulkan dari warga hendak disalurkan kembali kepada warga dalam wujud kredit. Dalam memenuhi kredit yang dimohon oleh para calon nasabah baik dari bank swasta ataupun dari bank pemerintah berupaya buat membagikan cicilan KPR yang disesuaikan dengan pendapatan para calon nasabahnya serta rumah yang hendak dibelinya.

PT. Bank Tabungan Negara merupakan bank yang ada di Sumatera Barat, Padang, merupakan bank yang bekerja sama dengan pihak devoloper untuk memudahkan kepada calon debitur dalam pemberian kredit kepemilikan rumah. PT. Bank Tabungan Negara selama ini dikenal masyarakat dengan produk kredit kepemilikan rumah. PT. Bank Tabungan Negara memberikan prosedur yang mudah, bunga yang rendah dan angsuran yang terjangkau dalam kredit kepemilikan rumah. KPR Subsidi adalah yang mempunyai tipe rumah maksimal dengan harga jual maksimal Rp 150.000.000. KPR lebih di minati oleh masyarakat karena harga jual rumah dan tingkat bunga yang rendah. Dalam pelaksanaannya, KPR memiliki suatu permasalahan yaitu timbulnya 
penunggakan pembayaran angsuran yang bisa menimbulkan kredit macet. Hal ini karena faktor pihak bank, debitur, dan lingkungan.

\section{Tabel 1}

Data jumlah nasabah KPR di bank PT. Bank Tabungan Negara Padang Tahun 2016-2020

\begin{tabular}{lrrr}
\hline No. & Tahun & $\begin{array}{l}\text { jumlah nasabah KPR } \\
\text { Tabungan Negara }\end{array}$ & di PT. Bank \\
\hline 1. & 2016 & 17.250 & \\
2. & 2017 & 16.010 & \\
3. & 2018 & 18.952 & \\
4. & 2019 & 22.000 & \\
5. & 2020 & 24.282 & \\
\hline
\end{tabular}

Sumber: PT. Bank Tabungan Negara Padang

Berdasarkan data pada tabel 1 diketahui bahwa pada tahun 2016 jumlah nasabah yang melakukan kredit kpr di bank PT. Bank Tabungan Negara sebanyak 17.250 namun pada tahun 2017 mengalami penurunan sebesar 16.010 selanjutnya pada tahun 2018 nasabah yang melakukan kredit kpr juga mengalami kenaikan yaitu sebesar 18.952 pada tahun 2019 mengalami kenaikan sebesar 22.000 dan pada tahun 2020 nasabah yang melakukan kredit kpr juga mengalami kenaikan sebesar 24.282

\section{METODE PENELITIAN}

\section{Metode Pengumpulan Data}

Untuk keperluan dalam melakukan penelitian ini pengumpulan data dapat dilakukan dengan dua cara yaitu :

a. Riset Kepustakaan ( Library Research)

Penelitian yang dilakukan keperpustaka agar memperoleh informasi yang relevan dengan pembahasan, informasi dapat diperoleh dari buku-buku ilmiah, laporan penelitian, karangan ilmiah, tesis dan sumber-sumber tertulis baik cetak maupun elektronik lain.

b. Riset Lapangan ( Field Research)

Datang langsung ke objek riset yang dipilih untuk mempelajari hasil data primer. Penelitian langsung ke lapangan ini akan dapat

\section{Metode Analisa Data} membantu penulis untuk melengkapi data- data yang dibutuhkan.

penulis menggunakan metode analisa data kualitatif, dimana metode ini menjelaskan secara deskriptif mengenai prosedur pemberian kredit KPR pada PT. Bank Tabungan Nagari Cabang Lubuk Buaya Padang.

\section{HASIL PENELITIAN DAN PEMBAHASAN \\ Pengertian Bank}

Bank Menuut Albertus, (2017) dalam (Fadli Alanshari, 2018) Bank merupakan lembaga usaha keuangan pasar yang didirikan berdasarkan persetujuan dari perusahaan untuk menerima simpanan uang serta pinjaman uang karna bisa menerbitkan surat hutang. 
Menurut Kasmir bank merupakan suatu badan usaha dimana kekayaannya dalam bentuk aset keuangan ( financial assets ), serta menginginkan keuntungan dan juga sosial jadi tidak hanya mencari keuntungan. (Kasmir, 2007:23) dalam (wulan angka sari, 2016).

Menurut Undang-Undng No 10 tahun 1998 , bank merupakan badan usaha yang menghimpun dana dari masyarakat dalam bentuk simpanan dan menyalurkannya dalam bentuk kredit dan bentuk lain guna untuk meningkatkan kehidupan rakyat banyak

\section{Pengertian PT. Bank Tabungan Negara}

PT. Bank Tabungan Negara, (Persero) merupakan Badan Usaha Milik Negara yang bergerak dibidang jasa Perbankan, yang kewajibannya adalah menjadi bank yang baik, melayani serta mendukung pembiayaan sektor perumahan melalui tiga produk utama yaitu perbankan syariah, bisnis dan syariah. (www.btn.co.id )

\section{Jenis - jenis Bank}

1. Jenis Bank dilihat dari segi kepemilikan yaitu:

1) Lembaga keuangan milik pemerintah Dimana surat pendirian perusahaan atau modal yang dimiliki pemerintah secara pribadi.

2) Lembaga keuangan milik swasta nasional. milik swasta nasional serta surat pendirian perusahaan dan pembagian laba

2 Dari segi status pembagian lembaga keuangan

1) Lembaga keuangan devisa, dapat melaksanakan pembayaran keluar negeri yang berhubungan dengan mata uang asing.

2) Lembaga keuangan non devisa Kebalikan dari lembaga keuangan devisa, dimana pembayaran yang dilakukan dalam satu negara.

\section{Fungsi Bank}

Menurut (Susilo, Triandoro dan Santoro, 2018) dalam (ZAKIYAH, 2019) bahwa bank berfungsi menampung dana masyarakat dan menyalurkan kembali untuk tujuan yang beraneka ragam atau yang biasa dikenal dengan fungsi Financial Intermediary.

Menurut Adli, (2012) dalam (Fadli Alanshari, 2018) Bank memiliki fungsi yang sama seperti lembaga lain. Fungsi bank Sebagai Agent of Trust bahwa aktivitas bank sebagai financial intermediary menjalankan fungsi atas dasar kepercayaan yang diterima oleh bank dari masyarakat kepercayaan agar bank mengelola dan mengamankan dana yang disimpan di bank tersebut.

\section{Pengertian Kredit}

Berdasarkan UU No. 10 tahun 1998 kredit merupakan penyalur uang atau tagihan yang bisa disamakan dengan itu, berdasarkan persejutuan dan kesepakan antara dua belah pihak dimana pihak peminjam harus melunasi hutang dalam jangka waktu tertentu dengan adanya bunga.

Kredit adalah penyalur uang atau permintaan yang bisa disamakan dengan itu, melalui persetujuan dan kesepakatan pinjaman yang dilakukan bank dengan pihak lain yang mengharuskan peminjam melunasi hutangnya dalam jangka waktu yang ditentukan beserta bunganya (Andriani \& Susanto, 2016) dalam (Shinta Oktavia Zalpi, 2018)

Menurut Fitri, (2014) dalam (Fadli Alanshari, 2018) Kredit adalah sesuatu yang dibutuhkan oleh masyarakat guna mendorong dan 
melancarkan aktivitas perdagangan, baik dalam bidang memproduksi barang maupun jasa dan juga untuk meningkatkan atau memenuhi kebutuhan konsumsi masyarakat

\section{Fungsi Kredit}

Macam-macam fungsi kredit adalah:

1. Kredit dapat meningkatkan daya guna uang dan barang.

2. Kredit sebagai alat stabilitas ekonomi.

3. Kredit sebagai jembetan meningkatkan pendapatan nasional.

4. Kredit juga sebagai alat hubungan ekonomi internasioal.

\section{Jenis- Jenis kredit}

Secara umum jenis-jenis kredit yang diberikan adalah:

1. Kredit Investasi merupakan kredit yang diberi kepada pengusaha atau penanaman modal.

2. Kredit Modal Kerja digunakan sebagai modal kerja jangka waktu tidak lewat dari satu tahun.

3. Kredit Perdagangan, kredit yang diberi kepada para pedangang dalam mempelancar kegiatan perdagangnya.

4. Kredit Produktif adalah kredit yang dipinjamkan untuk usaha dan dikembalikan dari hasil usaha yang dipinjamkan.

5. Kredit Profesi diberikan kepada kalangan profesional seperti dosen, dokter, atau pengacara

\section{Pengertian Prosedur}

Menurut Ida (2008:35) dalam (PRATIWI, 2019) Prosedur merupakan suatu kegiatan yang behubungan dengan yang dilakukan, bagaimana cara melakukannya, di mana melakukannya, dan yang mengerjakannya.

Menurut Mulyadi (1997:6) dalam (PRATIWI, 2019) Prosedur merupakan langkah pekerjaan yang melibatkan suatu departemen guna untuk menjanjikan pengelolaan yang berulang secara bersama.

\section{Pengertian Prosedur KPR}

Menurut Ira, (2015) dalam (Fadli Alanshari, 2018) Prosedur KPR merupakan langkah kegiatan yang klerikal, yang melibatkan beberapa orang dalam satu departemen atau lebih, dibuat untuk menjamin penanganan secara seragam transaksi suatu perusahaan yang terjadi secara berulangulang.

\section{PEMBAHASAN}

\section{Syarat dan ketentuan kredit}

Syarat dan Ketentuan sebagai berikut :

1. WNI sudah menikah atau berumur 21 tahun.

2. Usia pemohon tidak lebih dari 65 tahun pada saat pinjaman jatuh tempo. Untuk anggota ASABRI yang mendapatkan rekomendasi dari YKPP usia 80 tahun saat pinjaman jatuh tempo

3. Pemohon maupun suami atau istri tidak mempunyai tempat tinggal dan tidak pernah menerima bantuan pemerintah Tidak termasuk untuk TNI, Polri, PNS yang pindah tugas

4. Gaji atau penghasilan pokok tidak melebihi:
a. Rp 4 juta untuk rumah sejahtera tapak
b. Rp 7 juta untuk rumah sejahtera susun
c. Memiliki e-KTP yang terdaftar di dukcapil 
d. Memiliki NPWP dan SPT Tahunan PPh orang pribadi

e. wajib terdaftar di Kementerian PUPR

f. Spesifikasi rumah sesuai dengan peraturan pemerintah

1. Persyaratan Umum

a. Mengisi formulir permohonan KPR

b. Foto copy KTP suami/istri yang masih berlaku

c. Foto copy KK

d. Foto copy surat nikah

e. Foto copy tabungan BTN

f. Pas foto suami/istri warna $3 \times 4$ sebanyak 1 lembar

g. NPWP permohon

h. Foto copy sertifikat

i. Foto copy IMB

j. Pembayaran PBB yang masih berjalan

k. Formulir kementrian pekerjaa umum dan perumahan warga

2. Persyaratan Khusus

A. Bagi PNS

1) Foto copy perincian gaji/slip gaji dan amprah gaji terakhir pemohon 2 bulan terakhir

2) Kuasa pemotongan gaji yang di tanda tangani bendahara gaji dan di ketahui pimpinan instansi

3) Foto copy SK terakhir, TASPEN atau keterangan instansi lainnya

4) Rekening koran gaji minimal 6 bulan terakhir

B. Bagi Karyawan Swasta

1) Foto copy perincian gaji/slip gaji

2) Kuasa pemotongan gaji yang di tanda tangani bendahara gaji dan diketahui pimpinan instansi

3) Foto copy surat keputusan pengangkatan

4) Surat keterangan kerja dari perusahaan

5) Rekening koran gaji minimal 6 bulan terakhir

C. Bagi Wiraswasta

1) Foto copy SIUP/SITU/AKTA CV/ NPWP perusahaan jika ada perusahaan

2) Laporan jual beli dan usaha

3) Data pendukung lain (seperti fotocopyBPKB, bukti sewa toko dll)

4) Foto copy rekening bak lain 6 bulan terakhir

5) Foto copy pembukuan 6 bulan terakhir dan bon penjualan dan pembelian.

Prosedur pemberian kredit KPR PT. Bank Tabungan Negara Cabang Lubuk Buaya Padang

Prosedur pemberian kredit bank pada umumnya sama hanya saja perbedaan terletak pada persyaratanya dan tujuan yang ditetapkan oleh masing-masing bank, Pada PT. Bank Tabungan Negara Cabang Lubuk Buaya Padang Prosedur pemberian kredit Kpr pada nasabah adalah sebagai berikut: 
1. Permohonan Kredit dan verifikasi.

Prosedur pemberian kredit diawali dengan permohonan kredit atau pengajuan berkas-berkas persyaratan kredit. Setelah berkas diajukan oleh pemohon berkas tersebut diserahkan kepada petugas yang melakukan penyidikan berkas pinjaman. tugas ini berupa pengumpulan data permohonan kredit, pengecekan daftar hitam calon debitur (BI cheking) Penyidikan Berkas Pinjaman. Selanjutnya pihak Loan Service (LS) melakukan wawancara pertama dengan calon debitur wawancara ini berupa tentang penghasilan, jumlah anggota keluarga dll. Pada tahap ini formulir wawancara hanya dibuat satu rangkap.

2. Kelayakan Kredit

Pada tahap ini dokumen dan formulir permohonan kredit diserahkan kepada bagian kredit (seksi lapangan), seksi lapangan akan melakukan survey dan mencocokan data pada formulir pengajuan kredit sesuai kenyataan. Untuk melakukan analisa kredit sebaiknya analis kredit menganalisa kredit tidak hanya dari 3 pilar saja (ketepatan dalam membayar, prospek usaha debitur, dan kondisi keuangan debitur) melainkan dengan $5 \mathrm{C}$ yaitu:

a. Character (sifat)

b. Capacity (Kapasitas)

c. Condition of Economic (Kondisi ekonomi)

d. Collecteral (Jaminan)

Prosedur selanjutnya yaitu tahap wawancara 2 (dua), pada tahap wawancara 2 ini merupakan kegiatan perbaikan berkas jika mungkin ada kekurangan pada saat setelah di lakukannya on the spot di lapangan maka kekurangan tersebut dilakukan diwawancara 2.

3. Keputusan KPR

Dokumen yang telah disetujui diserahkan kepada direktur untuk diputuskan apakah disetujui atau di berhentikan (ditolak). Jika disetujui dokumen tersebut akan diotorisasi oleh direktur, Dokumen yang telah di otorisasi oleh direktur dibuatkan akta perjanjian antara pihak bank dengan pemohon kredit diadan notaris dengan ketentuan yang telah disetujui oleh kedua belah pihak.

4. Akad kredit

fasilitas kredit setelah proses pengukuhan jaminan, pembayaran semua jaminan yang ditetapkan selesai dan semua pembayaran yang ditetapkan oleh credit comite telah dipenuhi, maka akan dilakukan dropping fasilitas kredit. Setelah diberikan keputusan kredit bahwa kredit disetujui, pihak Loan service menerbitkan SP3K untuk penanda tanganan Akad kredit.

5. Pencairan Dana Kredit

Pencairan dana dilaksanakan ketika penanda tanganan surat perjanjian kredit selesai dan apabila debitur telah membuka rekening kredit. Jika Akad kredit telah selesai maka bank akan menyalurkan dana kredit yang umumnya Pencairan dana Kredit Pemilikan Rumah (KPR) Bersubsidi dicairkan melalui rekening Developer oleh petugas Loan Administration (LA) dan Transaction Processesing (TP). Kegiatan dilakukan maksimum 7 hari kerja. 


\section{Monitoring}

Tahap terakhir dari prosedur pemberian kredit yaitu monitoring. Monitoring ini merupakan aktivitas yang dijalankan setiap Account Manager untuk memonitor dan mengendalikan kegiatan debitur atau nasabah dalam arti yang seluas-luasnya. Monitoring kredit yang dilakukan pada PT. Bank Tabungan Negara cabang Lubuk Buaya Padang sudah baik dimana memiliki pejabat yang berwenang tersendiri untuk memantau rekening debitur setiap harinya.

Pada saat proses pengawasan bagian yang terkait ada yaitu Loan Service (LS) sebagai pihak yang memonitoring nasabah melalui sistem green screen dan ecoll dan CCRD sebagai petugas yang memberikan informasi mengenai keadaan debitur untuk kemudian ditindak lanjuti. Hal ini memperlihatkan pengendalian interen yang baik karena dalam proses monitoring ini tidak hanya dilkukan oleh satu bagian saja.

\section{SIMPULAN}

Berdasarkan pembahasan pada bab sebelumnya, maka prosedur pemberian kredit pada PT. Bank Tabungan Negara Cabang Lubuk Buaya Padang dapat disimpulkan Dalam Prosedur pemberian kredit KPR pada PT. Bank Tabungan Negara cabang Lubuk Buaya Padang sesuai dengan prosedur yang telah ditetapkan yaitu mulai dari 1) Mengajukan permohonan kredit dan verifikasi. dimana pengajuan berkas-berkas persyaratan kredit, Setelah berkas diajukan oleh pemohon berkas tersebut diserahkan kepada petugas yang melakukan penyidikan berkas pinjaman, Selanjutnya pihak Loan Service (LS) melakukan wawancara pertama dengan calon debitur. 2) Kelayakan Kredit. seksi lapangan akan melakukan survey dan mencocokan data pada formulir pengajuan kredit sesuai kenyataan. Dengan menyusun laporan analisa yang diperlukan yaitu berisi kesimpulan dan bahan pertimbangan untuk pengambilan keputusan. 3) Keputusan KPR. Dokumen yang telah disetujui diserahkan kepada direktur untuk diputuskan apakah disetujui atau di berhentikan (ditolak). Jika disetujui dokumen tersebut akan diotorisasi oleh direktur. 4) Akad Kredit. Setelah diberikan keputusan kredit bahwa kredit disetujui, pihak Lsoan service menerbitkan SP3K untuk penanda tanganan Akad kredit. Akad kredit dilakukan oleh calon debitur. 5) Pencairan dana, dilaksanakan ketika penanda tanganan surat perjanjian kredit selesai dan apabila debitur telah membuka rekening kredit Jika Akad kredit telah selesai maka bank akan menyalurkan dana kredit. 6) Monotoring, Tahap terakhir dari prosedur pemberian kredit yaitu monitoring. Monitoring ini merupakan aktivitas yang dijalankan setiap Account Manager untuk memonitor dan mengendalikan kegiatan debitur atau nasabah dalam arti yang seluasluasnya. 


\section{DAFTAR PUSTAKA}

Alanshari, F., \& Marlius, D. (2018). Prosedur Pemberian Kredit KPR Pada PT. Bank Tabungan Negara (Persero) TBK Cabang Pembantu Bukittinggi. https://doi.org/10.31227/osf.io/rsfhc

Amelia, L., \& Marlius, D. (2018). Pengendalian Kredit Dalam Upaya Menciptakan Bank Yang Sehat Pada PT. Bank Pembangunan Daerah Sumatera Barat Cabang Utama Padang. https://doi.org/10.31227/osf.io/kpc64

Asyari, A., \& Marlius, D. (2021). Proses Penyelesaian Kredit Bermasalah Pada PT. BPD Sumatera Barat Cabang Pasar Raya Padang. https://doi.org/10.31219/osf.io/3hfcr

Nursana Rizki Amelia Dan Hendri Maulana. (2016). Proses Pemberian Kredit Griya Multi Dan Pengelolaannya Pada Bank Btn Cabang Bogor. Jurnal Pengabdian Pada Masyarakat, 4.

Pratiwi, N. (2019). Prosedur Pemberian Kredit Kepemilikan Rumah (Kpr) Pada Pt. Bank Tabungan Negara, Tbk. Kcp. Maros. Pay Jurnal Keuangan Dan Perbankan., 1(1). Website: Http://Ejournals.Umma.Ac.Id/Index.Php/Pay

Shinta Oktavia Zalpi, R. S. (2018). Analisis Pemberian Kredit Pada Pt. Bank Perkreditan Rakyat Samudera Painan.

Wulan Angka Sari, Et All. (2016). Analisis Sistem Dan Prosedur Pemberian Kredit Kepemilikan Rumah (Kpr) Btn Bersubsidi Dalam Usaha Mendukung Pengendalian Manajemen Kredit. Jurnal Administrasi Bisnis (Jab), 41(1). Http://Administrasibisnis.Studentjournal.Ub.Ac.Id/Index.Php/Jab/Article/Vie wfile/1639/2023

Zakiyah, I. Q. (2019). Prosedur Pemberian Kredit Pemilikan Rumah Subsidi Kepada Nasabah Pada Bank Tabungan Negara Cabang 